\title{
Studies on Pulse Jet Engine by Wind Tunnel Testing
}

\author{
TOSHIHIRO NAKANO*, MICHAEL ZEUTZIUS, HIDEO MIYANISHI, \\ TOSHIAKI SETOGUCHI and KENJI KANEKO
}

Department of Mechanical Engineering, Saga University, 1 Honjo-machi, Saga-shi, Saga-ken, 840-8502, Japan

(Received in final form 1 March 1999)

\begin{abstract}
Simple design and efficiency make pulse jet engines attractive for aeronautical short-term operation applications. An active control system extends the operating range and reduces the fuel consumption considerably so that this old technology might gain a new interest. The results on wind tunnel experiments have been reported together with the impact of combustion mode (pulse or steady) on system performance.
\end{abstract}

Keywords: Active control, Compressible flow, Steady combustion, Propulsion, Pulse combustion, Wind tunnel testing

\section{INTRODUCTION}

Advantages of pulse jet engines (Foa, 1960) are their low weight and the generation of thrust even for start and low flight velocities, where a ramjet (steady combustion) is not able to generate any thrust at all. The well-known low specific impulse and fuel consumption higher than the one of a turbojet are the disadvantages of the pulse jet engines due to the missing pre-compression of the inlet flow. For short-term operation and applications where the turbojet is not the main propulsion and used only for the take-off, the obvious advantages of pulse jet engines used as start booster outweigh the disadvantages. Moreover, such engines offer the possibility to operate one combustor in ram-, pulse- and rocket-mode (Zeutzius et al., 1998a,b). Last wind tunnel tests with pulse jet engines were done in Germany by Schmidt (1950) and Staab (1954), but most of their results were getting lost during the war time. In addition, contemporary work (Barr et al., 1990) concentrates to pulse combustors as gas generators. Therefore, present investigations are focused to the wind tunnel testing and the development of an active control system for pulse jet engines to extend their operating range including ram- and rocket-mode.

\section{EXPERIMENTAL SET-UP}

The pulse jet engine used in wind tunnel experiments as shown in Fig. 1 has a length of $80 \mathrm{~cm}$ and a pipe diameter of $34 \mathrm{~mm}$. The engine runs with

\footnotetext{
*Corresponding author. Fax: +81-952-28-8587. E-mail: nakano@me.saga-u.ac.jp.
} 


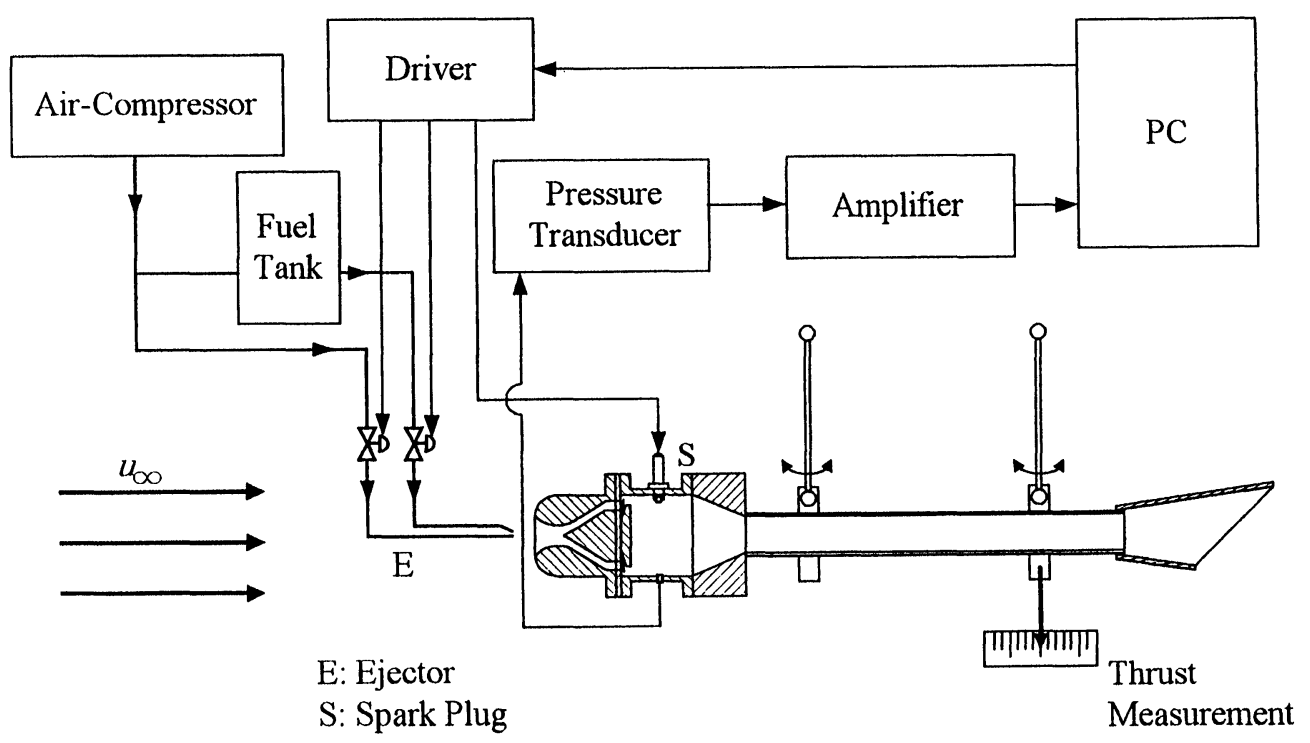

FIGURE 1 Pulse jet engine with wind tunnel suspension and propellant supply, experimental set-up.

gasoline that is vaporized by an air jet and charged to the combustor through the inlet equipped with aerovalve and reed valve, respectively. Because the state of the flow in front of the inlet influences considerably charging process and engine operation, an external flow around the propulsion is simulated with the Eiffel-type wind tunnel of Saga University having an open test section. Start and take-off conditions can be simulated with a free stream velocity of $u_{\infty}=35 \mathrm{~m} / \mathrm{s}$ at maximum. The pressure within the flow field was measured with a Prandtl tube, the combustion pressure with Piezo transducers, thrust and drag were obtained from the motion of the pendulum suspension of the engine.

The pulse jet engine (two-dimensional version) used for the feasibility study on the control system with a movable inlet cone (mass flow control) is shown in Fig. 2. Actual experiments with fuel and air rate as controller output were performed in open loop mode, it means no feed back to the controller. Kinetic energy of the exhaust flow, pressures, temperatures and flow rates are scheduled to be the feed back parameters to the controller for the closed loop run.

\section{RESULTS AND DISCUSSION}

\section{Engine Run and Performance}

The oscillation of the gas column in the pipe of a pulse jet engine is driven by the combustion as long as the charging of fresh mixture through the inlet is attenuated (Barr et al., 1990; Zeutzius et al., 1998a,b). Not only the charging but also the strength of the subsequent compression of the charged mixture by the gas column in the tailpipe depends on this pressure drop in the combustion chamber. The rising stagnation pressure at the inlet due to the increasing flight velocity lowers the charging attenuation and the obtainable minimum pressure because a higher air rate is supplied to the combustion chamber. The pressure amplitude declines and the flow through the engine approaches the ram-mode (constant pressure combustion) as shown in Fig. 3 for different flight velocities. Choking the air rate into the engine improves the performance of the engine. Since the charging and combustion mode depend strongly on the ratio of exit areas to combustor volume $A_{\mathrm{i}} / V_{\mathrm{i}}$ and $A_{\mathrm{N}} / V_{\mathrm{N}}$, an active engine control bases 


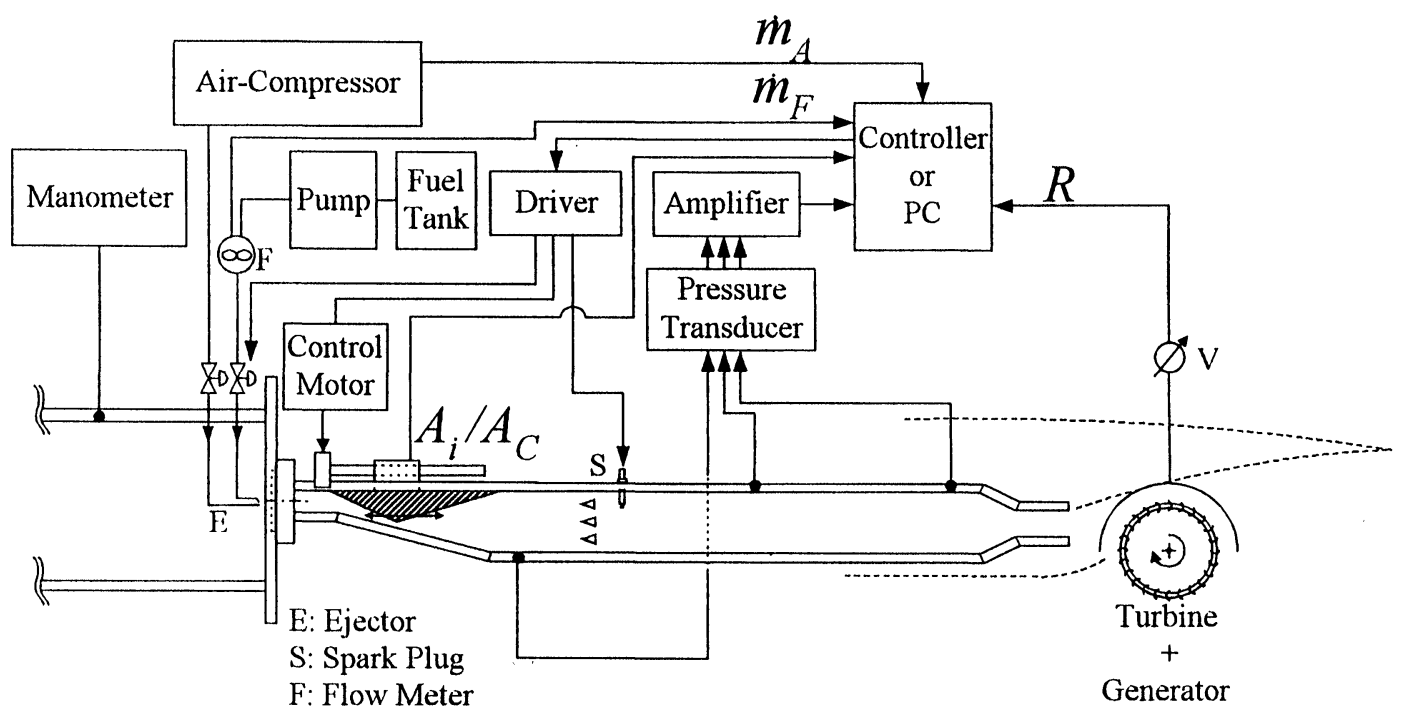

FIGURE 2 Two-dimensional combustor with control system; control parameter: fuel rate $\dot{m}_{\mathrm{F}}$, inlet cross section $A_{\mathrm{i}}$; controlled parameter: turbine speed $R$; feed back parameters: pressures, flow rates $\dot{m}_{\mathrm{A}}$, turbine speed, cross section.

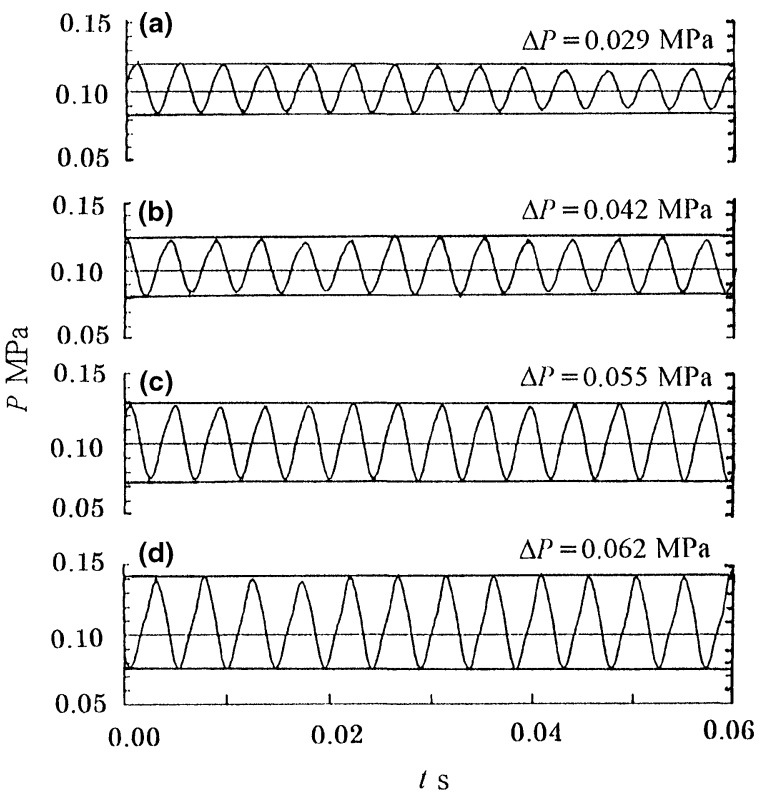

FIGURE 3 Pressure amplitudes $\Delta P$ of a pulse jet engine with reed valves for (a) $u_{\infty}=33.44 \mathrm{~m} / \mathrm{s}$, (b) $u_{\infty}=29.02 \mathrm{~m} / \mathrm{s}$, (c) $u_{\infty}=24.51 \mathrm{~m} / \mathrm{s}$, (d) $u_{\infty}=19.42 \mathrm{~m} / \mathrm{s}$.

upon a control of inlet and/or nozzle throat cross section.

Air and fuel rate as well affect the operation mode as can be seen from Fig. 4. The kinetic energy of the fuel gas was measured supplying the gas to a turbine whose speed is an indicator for the combustion efficiency. The superiority of the pulse combustion to the steady combustion and important tendencies can be seen from Fig. 4: (1) Low amount of air enclosed in the tail pipe can be accelerated to higher speeds $(L / d=4.8$, pipe length: $L$, pipe diameter: $d$ ) with the same amount of heat energy transferred in the combustor. (2) Higher friction in a longer tailpipe dependent on $L / d$ weakens the oscillation and the compression as well, so that a higher amount of air with lower kinetic energy can be pumped through the combustor. The maximum pumping capacity is obtained for non-reacting flows (thermal choking). Because a larger air mass is enclosed in a tail pipe with $L / d=13.2$, a higher amount of energy would be necessary to accelerate the gas. (3) If high-pressure gas is supplied to the propulsion it is obligatory to adjust the fuel rate not only to keep the mixing ratio inflammable but also to provide enough energy for the acceleration of the gas in the tail pipe.

The declination of the thrust shown in Fig. 5 depends on the pressure amplitude in the combustion chamber. Assuming a nearly harmonic nozzle exit pressure, the nozzle exit velocity $u_{\mathrm{N}}$ scales with 


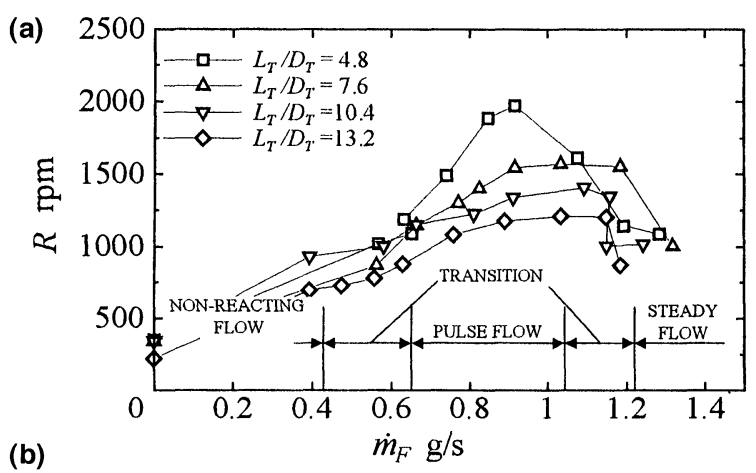

(b)

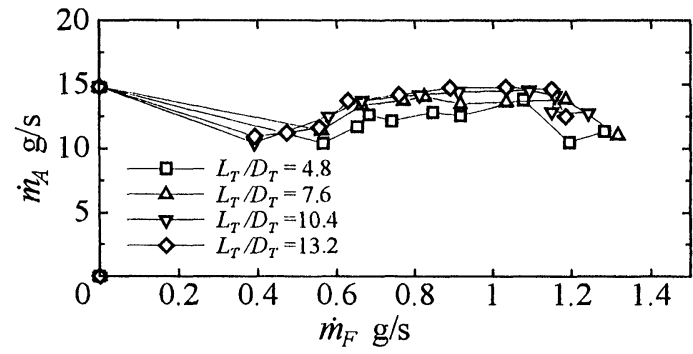

(c)

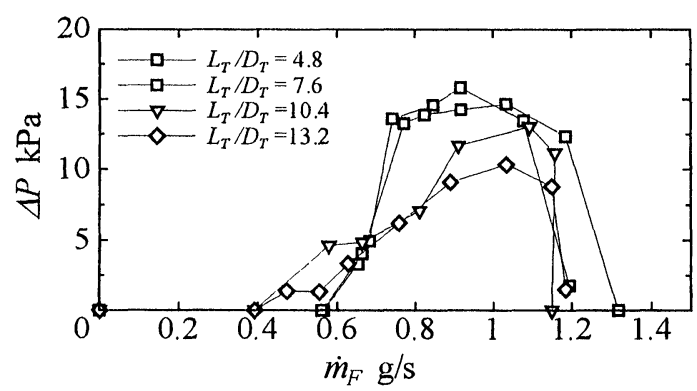

FIGURE 4 Capacity of pulse combustion for reduction of fuel consumption, (a) kinetic energy of the exhaust flow, (b) air flow rate and (c) pressure amplitude in dependence of fuel rate and tail pipe length.

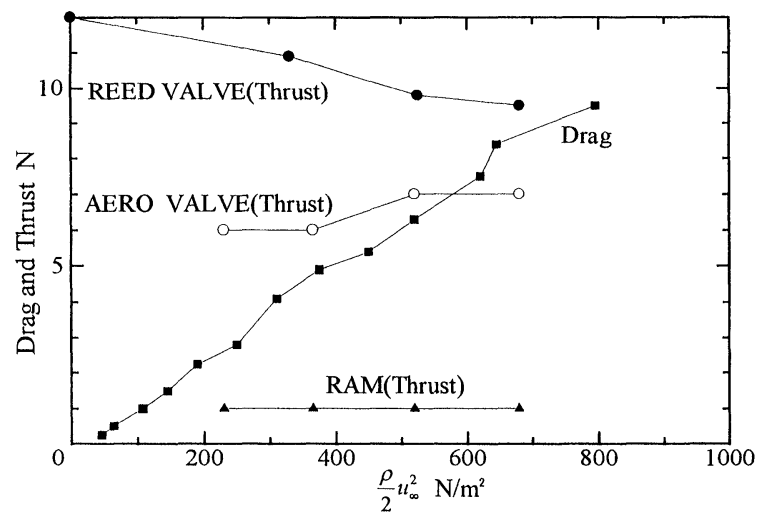

FIGURE 5 Thrust and drag dependent on the dynamic pressure. the pressure amplitude $\Delta P$ (ratio of specific heats: $\kappa$, sound velocity: $c$, mean combustion pressure: $P_{0}$ )

$$
\bar{u}_{\mathrm{N}}=\frac{2}{\pi} u_{\max }=\frac{2}{\pi} \frac{c \Delta P}{P_{0} \kappa} .
$$

Thrust $F$ and turbine speed concerning kinetic energy $R$ for pulse mode can be calculated with (air flow rate: $\dot{m}_{\mathrm{A}}$, combustion pressure amplitude: $\left.\Delta P_{\mathrm{C}}\right)$

$F=\dot{m}_{\mathrm{A}}\left(u_{\mathrm{N}}-u_{\infty}\right) \sim \dot{m}_{\mathrm{A}} \Delta P_{\mathrm{C}}$ and $R \sim \dot{m}_{\mathrm{A}} \Delta P_{\mathrm{C}}$

The ram thrust is caused by the fuel-air-ejector system (similar to an ejector pump) and fully negligible for low speed flight. Aerovalved engines produce a thrust of about $6 \mathrm{~N}$ slightly increasing with the stagnation pressure what is due to the increasing air flow rate. Engines with reed valves generate highest thrust of $12.5 \mathrm{~N}$ at a maximum, but the rising stagnation pressure difference between inlet and nozzle reduces the combustion pressure amplitudes due to the high air inflow into the combustor (Fig. 3). Concerning drag, redesigning the nacelle could reduce the high drag by half.

\section{Propulsion Installation Losses}

The requirements for an optimization of the pulse jet engine are contrary. While a choked inlet flow is necessary to sustain the pulse combustion and improve the thrust under high subsonic flight conditions, the installation losses might increase due to a higher spillage rate.

Spilling flow at the inlet can be seen from the flow field shown in Fig. 6 for a pulse jet engine with aerovalve. The free stream velocity of $24.8 \mathrm{~m} / \mathrm{s}$ is reduced to $14.3 \mathrm{~m} / \mathrm{s}$ in front of the inlet resulting in a spilling air rate in the order of magnitude of about $40 \%$ here for the incompressible external flow estimated with

$$
\frac{\Delta \dot{m}_{\infty}}{\dot{m}_{\infty}}=\frac{u-u_{\infty}}{u_{\infty}} .
$$




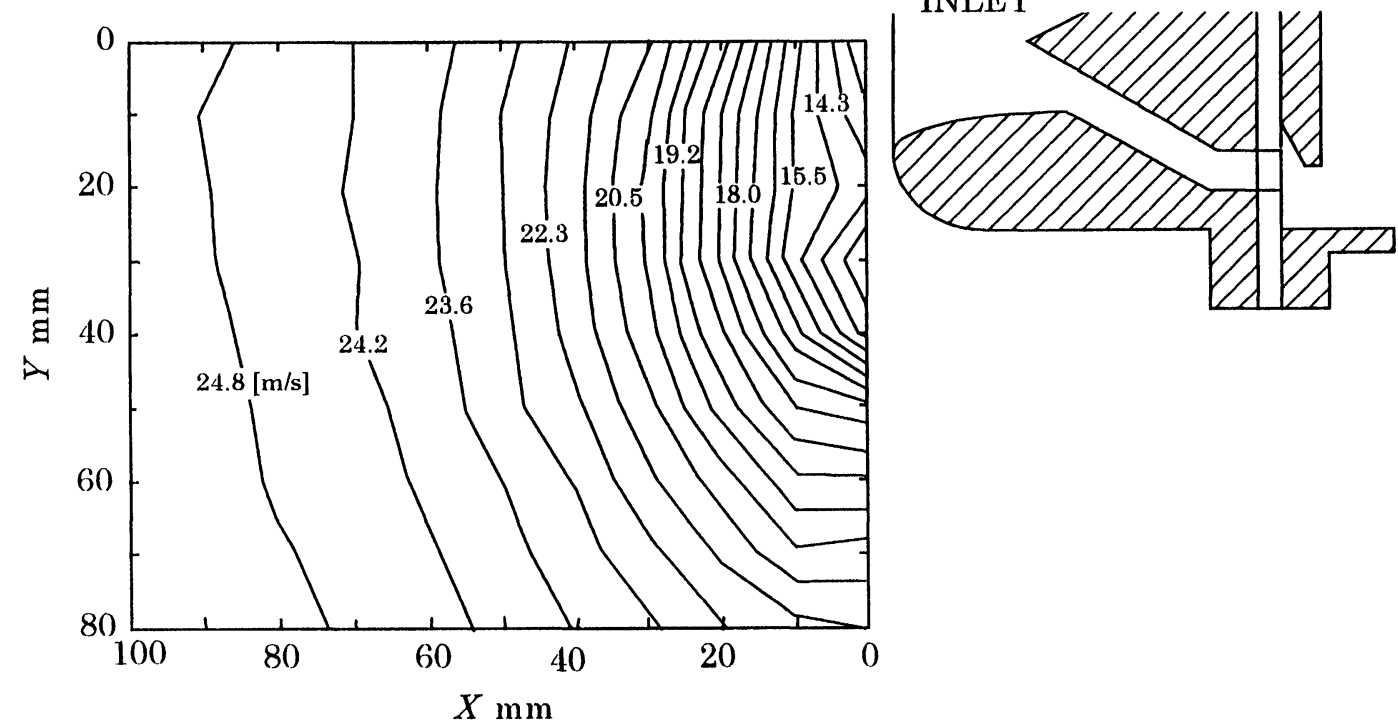

FIGURE 6 Velocity distribution in the inlet area for an aerovalved pulse jet.

A high integration of the propulsion in combination with a Busemann inlet (Zeutzius et al., 1998a,b; Staab, 1954) leads to a reduction of spillage drag and non-uniformity losses as well.

\section{Propulsion Control}

The pressure difference between inlet and nozzle exit is the reason why the flow turns in a steady mode and therefore, the design targets for the control system are:

(1) Extension of the engine operating range by choking the air rate through the engine.

(2) Keeping spillage drag as low as possible.

(3) Raising the nozzle/base pressure.

These requirements can be fulfilled with a control of the inlet flow rate (adaptation of cross section with movable inlet cone). The control law for a combustor run close to the design point is

$$
\begin{gathered}
\mathrm{d} R=\left(\frac{\partial R}{\partial \dot{m}_{\mathrm{F}}}\right) \mathrm{d} \dot{m}_{\mathrm{F}}+\left(\frac{\partial R}{\partial \dot{m}_{\mathrm{A}}}\right) \mathrm{d} \dot{m}_{\mathrm{A}} \text { with } \\
\mathrm{d} \dot{m}_{\mathrm{A}}=\left(\frac{\partial \dot{m}_{\mathrm{A}}}{\partial\left(A_{\mathrm{i}} / A_{\mathrm{C}}\right)}\right) \mathrm{d}\left(\frac{A_{\mathrm{i}}}{A_{\mathrm{C}}}\right) .
\end{gathered}
$$

The air rate can be calculated with the mass flow equation:

$$
\begin{aligned}
\dot{m} & =\rho A u \\
& =A \sqrt{2 P_{\mathrm{C}} \rho_{\mathrm{C}}} \sqrt{\frac{\kappa}{\kappa-1}\left\{\left(\frac{P}{P_{\mathrm{C}}}\right)^{2 / \kappa}-\left(\frac{P}{P_{\mathrm{C}}}\right)^{(\kappa+1) / \kappa}\right\}} .
\end{aligned}
$$

The fuel derivative $\partial R / \partial \dot{m}_{\mathrm{F}}$ is fitted into a higher order series for constant inlet cross section

$$
\frac{\partial R}{\partial \dot{m}_{\mathrm{F}}}=a_{n} \dot{m}_{\mathrm{F}}^{n}+\cdots+a_{2} \dot{m}_{\mathrm{F}}^{2}+a_{1} \dot{m}_{\mathrm{F}}+a_{0} .
$$

In contrast to the past, the operating range of flight vehicles propelled with pulse jet engine is extended using the inlet control system for Eq. (1) a stabilization of the operation mode and Eq. (2) an inclusion of rocket and ram mode in the propulsion operation (Fig. 7). For fixed geometry (standard operation) the fuel consumption is reduced by at least $20 \%$ of that of a steady combustion. While a small area ratio is beneficial for a high efficient combustion labeled with "E" in Fig. 7(c), it cannot 
(a)

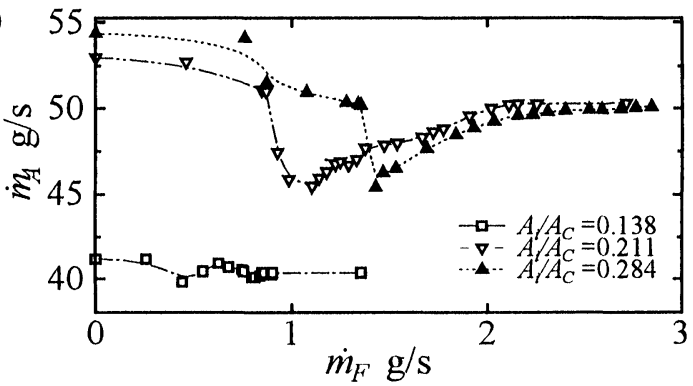

(b)

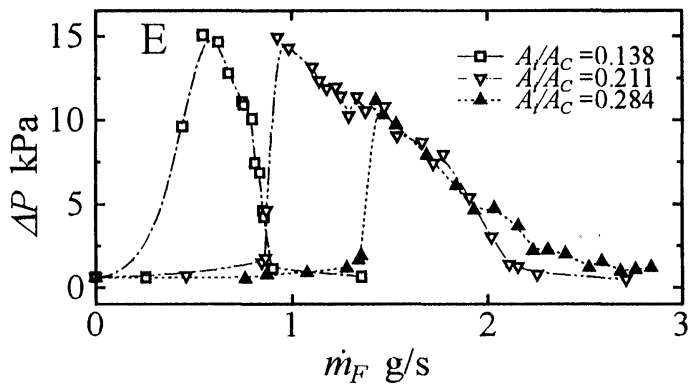

(c)

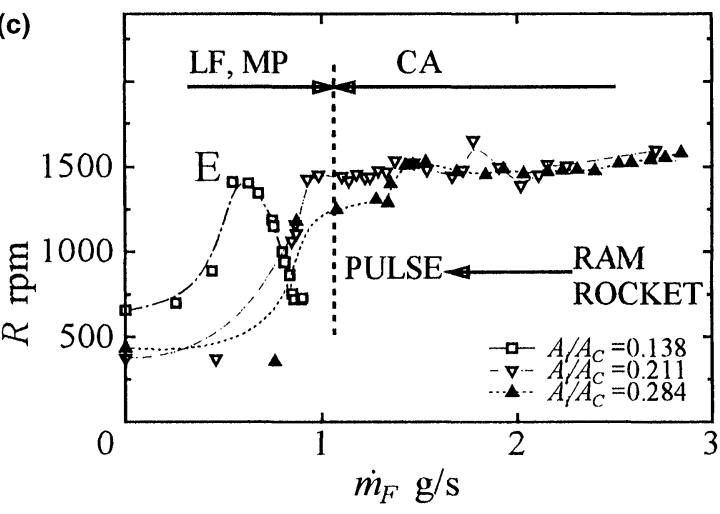

FIGURE 7 Two-dimensional combustor; (a) air rate, (b) amplitude, (c) turbine speed dependent on fuel rate, E: highest efficiency, LF: low fuel consumption, CA: constant area.

be used for a mode change in propulsion application. The subsequent drop of the kinetic energy for steady combustion is too high. For a smoothed change of the operation mode from pulse to steady combustion (ramjet), the inlet area should be enhanced to a higher value until the steady mode is reached. No drop of the kinetic energy is obeyed for a transition from pulse to steady mode (ram combustion) for larger cross sections. The propulsion can be switched to rocket mode by closing inlet and supplying oxygen from tanks to the combustor.

\section{CONCLUSIONS}

Wind tunnel tests were performed to show the impact of external flow on a pulse jet operation. The thrust of pulse jet engines with reed valve slightly decreases with increasing flight velocity. High stagnation pressure in front of the inlet turns the pulse flow into a steady one so that the benefit gained by the compression capacity of the gas column in the tail pipe is getting lost. The inlet air rate control used for choking the inlet flow improves thrust, extends operating range and makes ram (inlet open, steady combustion) and rocket (closed inlet, steady flow) operation possible. Using pulse combustion with inlet flow control reduces the fuel consumption by at least $20 \%$.

\section{NOMENCLATURE}

area

sound velocity

pipe diameter

thrust

tail pipe length

mass flow rate

order

pressure

rotational speed

time

velocity

volume

coordinates

spilling flow rate

pressure amplitude

ratio of specific heats

density

\section{Subscripts}

$\begin{array}{ll}\text { A } & \text { air } \\ \text { C } & \text { combustion chamber } \\ \text { F } & \text { fuel } \\ \text { i } & \text { inlet } \\ \text { N } & \text { nozzle }\end{array}$




\section{mean}

$\infty \quad$ ambient

0 stagnation

\section{References}

Barr, P.K., Keller, J.O., Bramlette, T.T. and Westbrook, C.K. (1990), Pulse combustor modeling-demonstration of the importance of time characteristics, Combustion and Flame, 82(1), 252-269.

Foa, J.V. (1960), Elements of Flight Propulsion, John Wiley \& Sons Inc., New York, London, pp. 368-389.
Schmidt, P. (1950), Die Entwicklung der Zuendung periodisch arbeitender Strahlgeraete, VDI-Zeitschrift, Germany, 92(6), 393-399.

Staab, F. (1954), Strahltriebwerke auf Grundlage des Schmidtrohres, Zeitschrift fuer Flugwissenschaften, Germany, 2(6), 129-144

Zeutzius, M., Setoguchi, T., Terao, K. and Miyanishi, H. (1998a), A Propulsion for hypersonic space plane, Proc. 8th Int'l. Space Planes and Hypersonic Systems and Technologies Conf., AIAA 98-1531, Norfolk, pp. 185-195.

Zeutzius, M., Setoguchi, T., Terao, K., Matsuo, S., Nakano, T. and Fujita, Y. (1998b), Active control of twin pulse combustors, AIAA' Journal, 36(5), 1-7. 

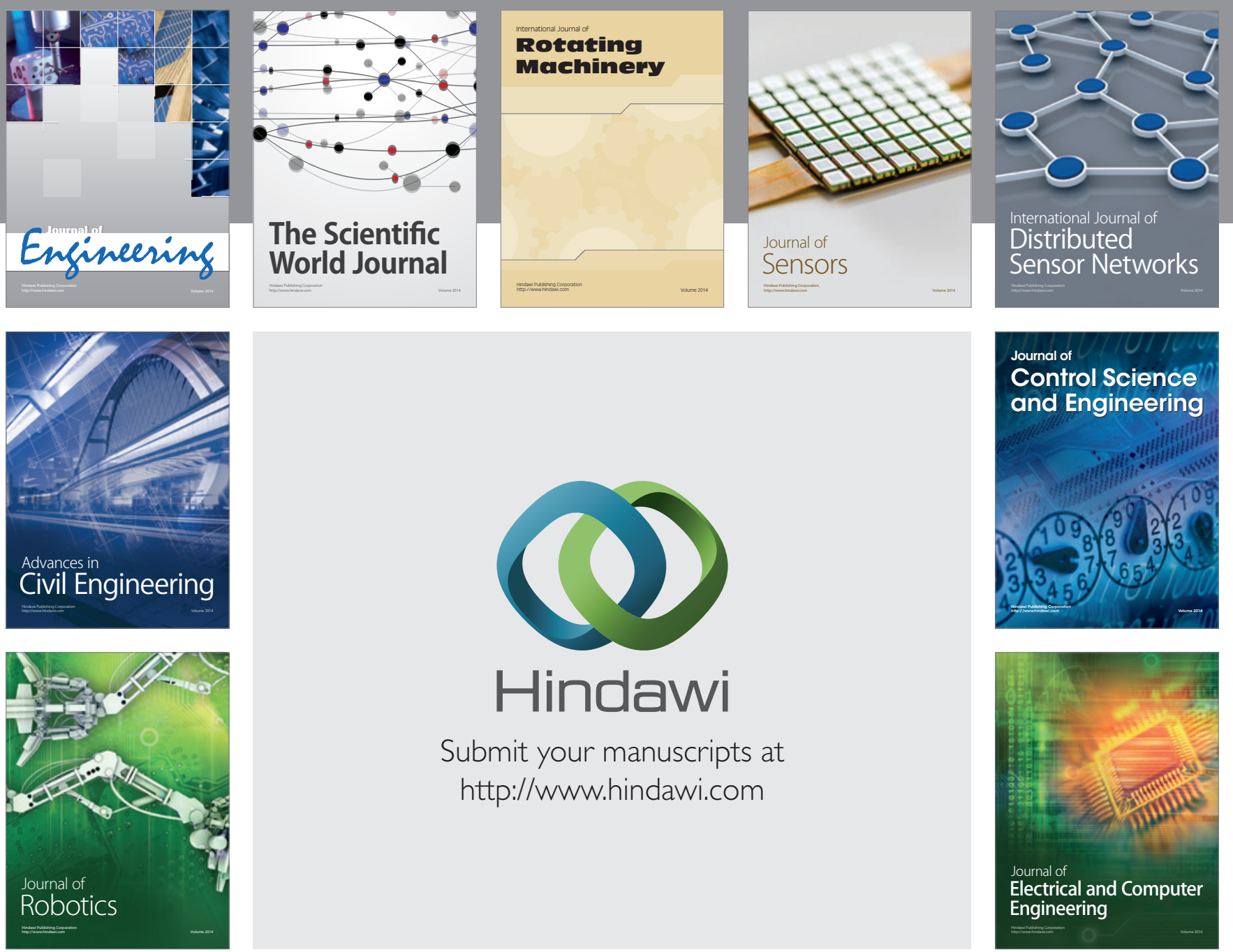

Submit your manuscripts at

http://www.hindawi.com
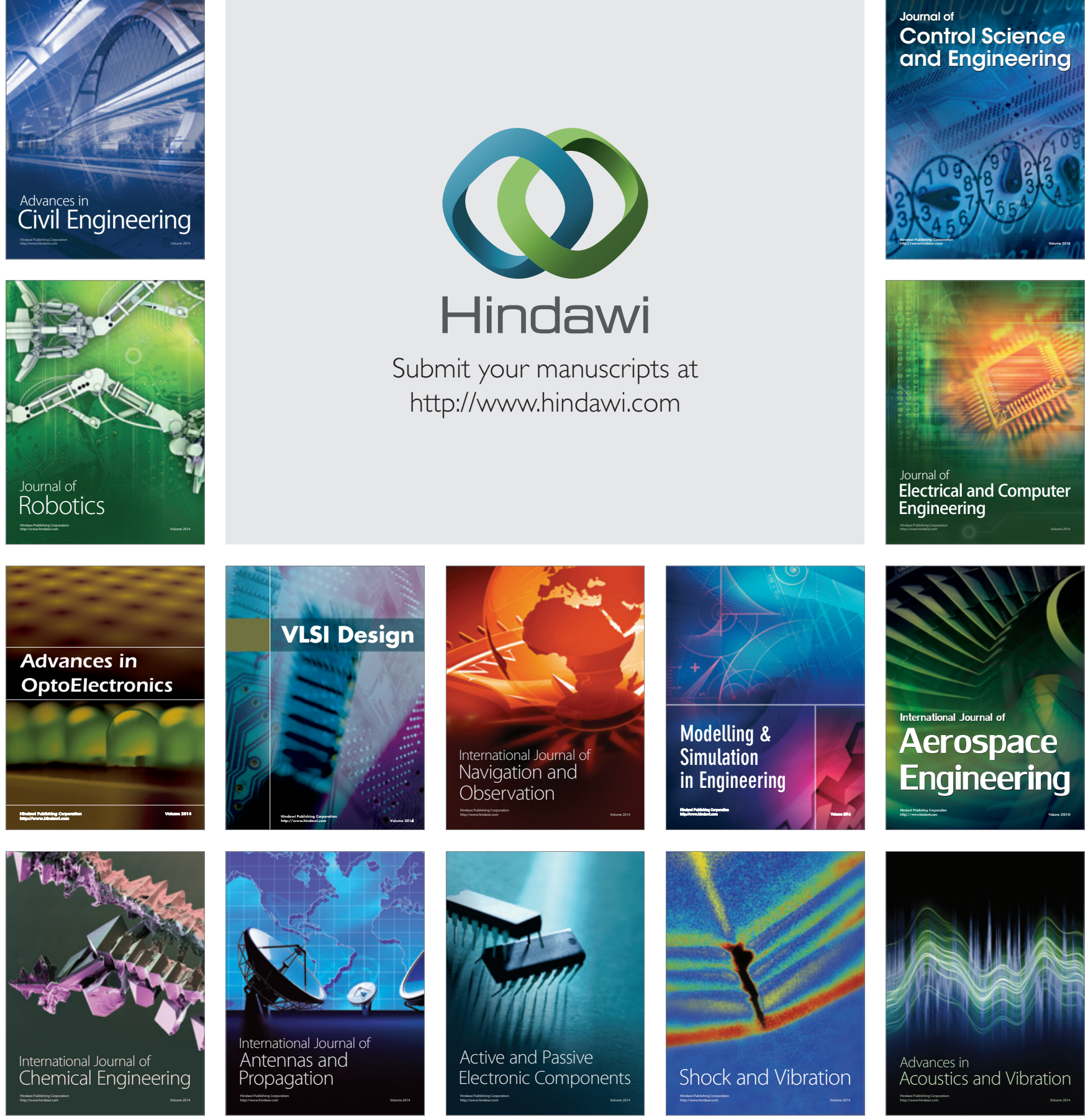